\title{
Adequacy of Scrubbing, Gowning and Gloving Among Operating room Nurses
}

\author{
Ms. Anita Kiruba Jeyakumar ${ }^{1}$, Ms. Sonia Sabu ${ }^{2}$, Ms. Florence Segeran ${ }^{3}$. \\ ${ }^{I}$ (OR Nursing Department, College of nursing, Christian Medical College, India) \\ ${ }^{2}$ (OR Nursing Department, College of nursing, Christian Medical College, India) \\ ${ }_{3}^{3}$ (OR Nursing Department, College of nursing, Christian Medical College, India)
}

\begin{abstract}
The patient care in the operating rooms $(O R)$ is delivered by a team. Nurse is the primary member of the team. A uniform practice among nurses will ensure standard of care. One important practice that forms the base in the prevention of infection is surgical scrubbing, gowning and gloving. The correct performance of these procedures help to protect a patient from infection. All members of the sterile surgical scrub team are required to perform a surgical hand scrub and don sterile gown and gloves before touching sterile equipment or the sterile field. The prevention of surgical wound infections has been a primary concern of the operating room (OR) team for more than a century. The traditional strategy for prevention, in addition to good surgical technique itself, has been scrupulous adherence to classic aseptic practice: scrubbing, gloving, barrier clothing and drapes, instrument sterilization, and a disciplined ritual designed to protect the integrity of the sterile field. Therefore, surgical aseptic technique is one that is subject to constant change and hence a continuous research on this topic is essential to keep abreast with the changing trends in the field of surgery to enhance quality patient outcome.
\end{abstract}

Keywords: Gloving, Gowning, OR nurses, Practice.

\section{Introduction}

The traditional strategy for prevention, in addition to good surgical technique itself, has been scrupulous adherence to classic aseptic practice: scrubbing, gloving, barrier clothing and drapes, instrument sterilization, and a disciplined ritual designed to protect the integrity of the sterile field. Therefore, surgical aseptic technique is one that is subject to constant change and hence a continuous research on this topic is essential to keep abreast with the changing trends in the field of surgery to enhance quality patient outcome. Cruse and Foord ${ }^{1}$ showed that aseptic transgressions as punctured gloves are much less important than such uncontrollable factors as the type of wound (clean, contaminated, or dirty), and the patient's age, health, and hospitalization history. Above all, most postsurgical infections are endogenous in origin and beyond control by such techniques as masking, gowning, and gloving. Walter" and Mogio et al"attribute $80 \%$ and $77 \%$ of wound infections, respectively, to endogenous agents that were not acquired in the OR.

Nevertheless, breaks in aseptic technique cannot be dismissed as inconsequential. If $80 \%$ of the infections are endogenous, $20 \%$ can be traced to the OR and can therefore be minimized by proper technique. The purpose of this study is to assess the adequacy of practice regarding scrubbing, gowning and gloving and also associate selected demographic variables and practice regarding scrubbing, gowning and gloving among OR nurses. The literature and hospital folklore are replete with anecdotal studies such as these. However, there are no data available to answer the following questions: What breaks in surgical asepsis actually occur? Do some occur more frequently than others? Are there individual patterns, ie, do certain persons tend to transgress certain rules or transgress more rules more frequently than others? Is there any event-response relationship between aseptic transgressions and infection incidence, ie, are some breaks more serious than others or is it a matter of the number of transgressions during a specific procedure?

Though prescribed steps in procedure for scrubbing, gowning and gloving are available, there seems to be a great deal of breach in the procedure among the OR team members. Hence a continuous research on this topic is essential to maintain standard operating procedures across the surgical team. This article is an effort to assess the adequacy of practice regarding scrubbing, gowning and gloving among OR nurses. This also attempts to keep abreast with the changing trends in aseptic techniques to enhance quality patient outcome.

\section{Materials and methods}

After a thorough review of the literature and extensive interviews with recognized authorities in surgical asepsis, 30 criteria that could be judged on a yes-or-no basis were selected. This observational checklist which was prepared based on the procedure manual. Content validity of the checklist was done by 2 experts in Nursing, 1 Anaesthetist (Head) and 1 Surgeon (OR steering committee chairperson). The Content Validity Index (CVI) is 0.97. This observational checklist contains 15 items on Scrubbing, 10 items on gowning, 5 items on 
closed gloving and 5 items on open gloving, with every Yes scoring 1 and No scoring 0 . The total score will be 30. The scores were interpreted as $>90 \%$ being very good, $70 \%-90 \%$ as good and $<70 \%$ to be poor.

One of us acted as an observer and recorded infractions on a physician-by-physician, case-by-case basis. A certain amount of subjectivity, inconsistency, and bias was expected at the beginning. With experience, however, observer bias should be reduced. The observer used Non- probability purposive sampling technique to identify the samples for study. One day prior to the observation it was made sure that the selected OR nurses were on duty. Each participant under study were given a sample number. The practice regarding scrubbing, gowning and gloving was assessed by using the observational checklist. Non participatory observation technique was used. Around 70 samples of nurses were assessed.

\section{Results}

The collected data was analyzed and the results are as follows:

Table: 1 - Distribution of nurses according to their demographic characteristics ( $\mathrm{n}=70$ )

\begin{tabular}{|c|c|c|c|}
\hline S.No & Demographic Variables & \multicolumn{2}{|c|}{ Distribution of Nurses } \\
\hline \multirow{4}{*}{1.} & \multirow[b]{2}{*}{$\begin{array}{l}\text { Age group (years) } \\
21-25\end{array}$} & No. & $\%$ \\
\hline & & 42 & 60 \\
\hline & $26-35$ & 20 & 28.6 \\
\hline & $36-45$ & 8 & 11.4 \\
\hline \multirow[t]{2}{*}{2.} & $\begin{array}{l}\text { Gender } \\
\text { Male }\end{array}$ & 4 & 5.7 \\
\hline & Female & 66 & 94.3 \\
\hline \multirow[t]{2}{*}{3.} & $\begin{array}{l}\text { Qualification } \\
\text { B.Sc. }\end{array}$ & 2 & 2.9 \\
\hline & Diploma & 68 & 97.1 \\
\hline \multirow[t]{4}{*}{4.} & $\begin{array}{l}\text { Experience (years) } \\
1-5\end{array}$ & 38 & 54.3 \\
\hline & $6-10$ & 19 & 27.1 \\
\hline & $11-15$ & 7 & 10 \\
\hline & $16-20$ & 6 & 8.6 \\
\hline
\end{tabular}

$60 \%$ (44) of the Nurses under study were in the age group between $21-25$ years. $94.3 \%$ (66) of the Nurses were females. About $97.1 \%$ (68) of the nurses were Diploma holders. 54.3\% (38) of them had a clinical experience in OR for 1-5 years.

Table: 2 - Distribution of adequacy of practice regarding scrubbing, gowning \& gloving among OR Nurses

\begin{tabular}{|l|l|l|}
\hline S.No & Variables & \% \\
\hline 1. & Scrubbing & 75.1 \\
\hline 2. & Gowning & 74 \\
\hline 3. & Gloving & 98.6 \\
\hline
\end{tabular}

Scrubbing practice among the OR nurses was $75.1 \%$ and gowning practice among OR nurses was $74 \%$ which is good. The gloving practice among the OR nurses was identified as $98.6 \%$ which is very good $21 \%$ (15) of the OR nurses were from orthopedic specialty.

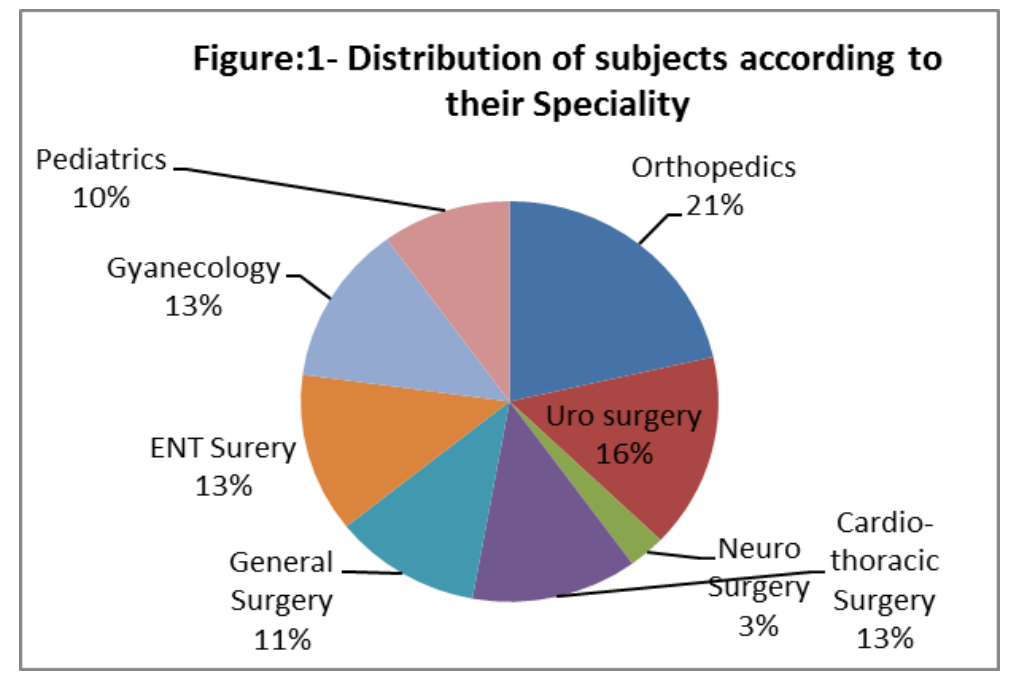


Table: 3- Distribution of overall practice regarding scrubbing, gowning \& gloving among OR Nurses $(n=70)$

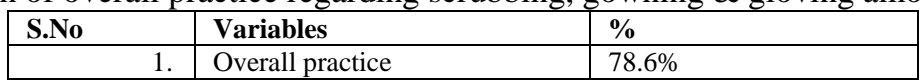

The overall Scrubbing, gowning and gloving practice among OR nurses was $78.6 \%$ which is good

Table: 6 - Association between selected demographic variables and scrubbing, gowning \& gloving practice

\begin{tabular}{llllllll} 
& & \multicolumn{9}{c}{$(\mathrm{n}=70)$} \\
S. No & Variables & \multicolumn{2}{c}{ Scrubbing } & \multicolumn{2}{c}{ Gowning } & \multicolumn{2}{c}{ Gloving } \\
& & $\boldsymbol{\chi}^{\mathbf{2}}$ & $\mathbf{p}$-value & $\boldsymbol{\chi}^{\mathbf{2}}$ & \multicolumn{1}{c}{ p-value } & $\boldsymbol{\chi}^{\mathbf{2}}$ & p-value \\
1. & Age & 1.50 & 0.946 & 8.78 & 0.802 & 21.7 & 0.992 \\
2. & Experience & 14.5 & 0.644 & 7.91 & 0.659 & 13.5 & 0.999 \\
3. & Educational Qualification & 3.98 & 0.912 & 2.71 & 0.744 & 0.266 & 0.876
\end{tabular}

Table: 6 shows no association between selected variables and scrubbing, gowning \& gloving practice among OR nurses

\section{Discussion}

This study was conducted with a core purpose of assessing the practice regarding scrubbing, gowning and gloving among OR nurses. It was also intended to identify association among selected variables and the knowledge and practice. Around 70 nurses participated in this study. Frequency, percentage and chi square were used to analyze the data. The demographic variables assessed were age, gender, qualification and experience. Analysis of the variables showed $60 \%$ (44) of the Nurses under study were in the age group between 21-25 years. $94.3 \%$ (66) of the Nurses were females. About $97.1 \%$ (68) of the nurses were Diploma holders. 54.3\% (38) of them had a clinical experience in OR for 1-5 years. One of the objectives was to assess the practice regarding scrubbing, gowning and gloving among OR Personnel. The present study assessed the practice regarding scrubbing, gowning and gloving among OR nurses, using an observational checklist which consisted of 15 items on scrubbing, 10 items on gowning and 5 items on gloving, with a maximum score of 30 . Higher scores revealed very good practice. It was found that scrubbing practice among the OR nurses was $75.1 \%$ and gowning practice among OR nurses was $74 \%$ which is good. The gloving practice among the OR nurses was identified as $98.6 \%$ which is very good. Another objective was to associate selected demographic variables with the practice regarding scrubbing, gowning and gloving among OR personnel. The present study associated the practice regarding scrubbing, gowning and gloving among OR nurses, using Chi square and identified that there were no significant associations.

During the study it was observed that most of the samples scrubbed for less than 2 minutes, with the recommended solution, but using straight strokes. All of them gave more time to scrub the hand and inbetween the digits that was acceptable. Most of them failed to scrub 2 inches below elbow. All of them were casual in doing the scrubbing. There is no study supporting these findings.

Out of 70 nurses, $77.1 \%$ (54) of them preferred to use reusable gown and $22.9 \%$ (16) of them disposable gown. Using of reusable gowns requires maintenance and manpower from washing, to folding to autoclaving and distributing. The technique to tie a wraparound requires an about turn, that poses risk for making the adjacent sterile articles, unsterile. During the study it was observed that few of the nurses failed to untie the wraparound before draping the trolley. It was also observed that they used sterile bundles as a hold to wrap around the side piece. These practices defy the principles of asepsis that is, anything below waiste, beyond vision and above the head must be considered unsterile, and also sterile items when coming into contact with an unsterile item becomes unsterile.

Using a sterile disposable gown eliminates the above flaws and makes it easier to wear and adhere to the principles of asepsis because length is medium, there is no wraparound, and there is a card that can be handed to either a scrub nurse or circulating nurse to finally secure it. The water resistant layers assure total sterility, because, after scrubbing, the investigator observed that the OR scrubs become wet and water from the wet scrubs seep through the sterile reusable gown, but not with the sterile disposable gown. This adds to its advantage.

Out of 70 nurses, $74.3 \%$ (52) of them used open gloving and $25.7 \%$ (18) of them used closed gloving technique. Though the open gloving technique is easier than closed gloving technique, there is a risk of contaminating the sterile glove with the open gloving technique. Closed gloving technique eliminates contamination. Closed gloving techniques were followed by few senior nurses and almost all junior nurses. 


\section{Conclusion}

The relationship between modern aseptic practice and postsurgical infection control is a classic enigma of epidemiology. Many precautions, rituals, and procedures have been introduced and implemented during the last century without any real validation of their efficacy. Certainly not all precautions are of equal importance; some are probably essential and others may be irrelevant. Compliance with the overall practice regarding scrubbing, gowning and gloving among OR Nurses was adequate, there's still a need for rigorous training towards excellence in this area. The same study can be conducted on a larger sample size.

\section{References}

[1]. Major RH: A History ofMedicine. Springfield, Ill, Charles C Thomas Publisher, 1954

[2]. Earle AS: The germ theory in America: Antisepsis and asepsis 1867-1900. Surgery 1969;65:508-522.

[3]. Wangensteen $\mathrm{OH}$, Wangensteen SD, Klinger CF: Some pre-Listerian and post-Listerian antiseptic wound practices and the emergence of asepsis. Surg Gynecol Obstet 1973;137: 677-702.

[4]. Lowbury EJL, Blowers R, Cunliffe AC, et al: Aseptic methods in the operating suite: A report to the Medical Research Council. Lancet 1968:1:705-709, 763-768, 831-839.

[5]. Atkinson LJ, Kohn ML: Berry and Kohn's Introduction to Operating Room Technique, ed 12. New York, McGraw-Hill Book Co, 2014.

[6]. Association of Operating Room Nurses Standards Committee: AORN Standards of Practice. Denver, Association of Operating Room Nurses, 2015

[7]. Altmeier WA: Surgical infections: Incisional wounds, in Bennet JV, Brachman PS (eds): Hospital Infections. Boston, Little Brown \& Co,1979, pp 287-306

[8]. Beck WC, Deshmukh N: Surgical infections, in Grll=o"\schelD (ed): Hospital-Associated Infections in the General Hospital Population and Specific Measures of Control. New York, Marcel Dekker Inc, 2000, pp 1-24.

[9]. Laufman H: The control of operating room infection: Discipline, defense mechanisms, drugs, design, and devices. Bull NY Acad Med 1978;54:465-483.

[10]. Walter CW: The surgeon and postoperative wound infection. Arch Surg 1979;114:769-770.

[11]. Cruse PJE, Foord R: A five-year prospective study of 23,649 surgical wounds. Arch Surg 1973;107:206-210.

[12]. Mogio M, Goldner JL, McCollum DE, et al: Wound infections in patients undergoing total hip arthroplasty. Arch Surg 1979; $114: 815823$

[13]. Walter CW, Kundsin RB: The airborne component of wound contamination and infection. Arch Surg 1973;107:588-595.

[14]. Feagin JA Jr: Bacteriology of the operating room with the use of helmet aspiration systems. Arch Surg 1979;114:790-792. 